\title{
Assessment of Common Soybean-Infecting Viruses in Ohio, USA, Through Multi-site Sampling and High-Throughput Sequencing
}

\author{
Junping Han, Department of Plant Pathology, Ohio Agricultural Research and Development Center, The Ohio State University, Wooster \\ 44691; Leslie L. Domier, United States Department of Agriculture, Agricultural Research Service, Department of Crop Sciences, University \\ of Illinois, Urbana 61810; and Bryan J. Cassone, Anne Dorrance, and Feng Qu, Department of Plant Pathology, Ohio Agricultural Research \\ and Development Center, The Ohio State University, Wooster 44691
}

Accepted for publication 20 May 2016. Published 10 June 2016.

\section{ABSTRACT}

Han, J., Domier, L. L., Cassone, B. J., Dorrance, A., and Qu, F. 2016. Assessment of common soybean-infecting viruses in Ohio, USA, through multisite sampling and high-throughput sequencing. Plant Health Prog. 17:133-140.

Multi-site sampling was conducted during 2011 and 2012 to assess the scope of virus disease problems of soybean in Ohio, USA. A total of 259 samples were collected from 80 soybean fields distributed in 42 Ohio counties, accounting for more than $90 \%$ of major soybean-growing counties in Ohio. A high-throughput RNA-Seq approach was adopted to identify all viruses in the samples that share sufficient sequence similarities with known plant viruses. To minimize sequencing costs, total RNA extracted from up to 20 samples were first pooled to make up regional pools, resulting in eight regional pools per year in both 2011 and 2012. These regional pools were further pooled into two yearly master pools of RNA, and sequenced using the Illumina's HiSeq2000 platform.
Bioinformatic analyses of sequence reads led to the identification of signature sequences of nine different viruses. The originating locations of these viruses were then mapped with PCR or RT-PCR. This study confirmed the widespread distribution of Bean pod mottle virus, Soybean vein necrosis virus, Tobacco ringspot virus, and Tobacco streak virus in Ohio. It additionally revealed occasional association of Alfalfa mosaic virus, Bean yellow mosaic virus, Clover yellow vein virus, Soybean mosaic virus, and Soybean Putnam virus with Ohio soybean. This is the first statewide survey of soybean viruses in Ohio, and provides the muchneeded baseline information for management of virus diseases of soybean.

\section{INTRODUCTION}

Soybean (Glycine max L. Merr.) provides essential nutrients, among them oil and protein, to both humans and food animals, and is also an important source of bioenergy (Wilson 2008). Additionally, due to its relative amenability to mass-scale production and its comparative profit potential, soybean production accounts for a substantial component of farmer incomes in the United States and many other countries around the world (Wilson 2008). Like other major crops, soybean is a host of diverse microbial pathogens including many viruses that can cause serious yield losses and/or seed quality deteriorations (Ghabrial et al. 1977; Harrison et al. 2005; Giesler and Ziems 2006; Bradshaw et al. 2008). A number of viruses have been reported to infect soybeans. Among them, the bean leaf beetletransmitted Bean pod mottle virus (BPMV) has been known to be a major soybean pathogen in the United States for many years and many isolates have been shown to cause diseases of varying severities (Giesler and Ziems 2006; Zhang et al. 2007). Soybean mosaic virus (SMV) is both seed- and aphid-transmitted, and can limit soybean yield potentials, although effective resistance sources for SMV are available (Hill et al. 2007; Gagarinova et al. 2008). Other viruses including Alfalfa mosaic virus (AMV), Soybean dwarf virus (SbDV), and Tobacco ringspot virus (TRSV), and Tobacco streak virus (TSV) have also contributed to

Corresponding author: Feng Qu. Email: qu.28@osu.edu.

doi:10.1094/PHP-RS-16-0018

C 2016 The American Phytopathological Society yield losses in soybean (Harrison et al. 2005; Giesler and Ziems 2006; Hill and Whitham 2014). More recently, Soybean vein necrosis virus (SVNV) has been characterized and subsequently reported in many states, although its impact on soybean yields has yet to be assessed (Zhou et al. 2011; Zhou and Tzanetakis 2013). Finally, Clover yellow vein virus (ClYVV), Bean yellow mosaic virus (BYMV), and Soybean yellow mottle virus (SYMV) have been reported to infect soybean in other countries, but their presence in soybean fields in the United States remains to be carefully assessed (Sasaya et al. 1997; Harrison et al. 2005; Campos et al. 2014; Kyrychenko 2013).

Until recently, identification of viruses in plants mostly relied on serological (e.g., enzyme-linked immune-absorbance assay [ELISA] or immune-strips) or nucleic acid-based (e.g., polymerase chain reaction [PCR] or reverse transcription [RT]PCR) approaches, with occasional electron microscopic (EM) inspection of particle morphology (Boonham et al. 2014). Serological assays rely on availability of specific antibodies, and thus could only be used to determine the presence of specific viruses in given samples. Similarly, PCR-based methods depend on the knowledge of specific nucleotide sequences, and are therefore limited to the confirmation of known viruses as well. On the other hand, the EM approach requires expensive, highmaintenance instruments, and provides limited insights beyond virion morphology. Therefore, without additional investigations in a specialized molecular biology lab, the above methods rarely lead to the characterization of new viruses.

This bottleneck of virus discovery is now being overcome with the advent of high-throughput sequencing technologies (Boonham et al. 2014; Kehoe et al. 2014). Notwithstanding differences in 
specific designs, all high-throughput sequencing platforms use universal adaptors to tag DNA fragments of unknown sequences and anchor them to solid surfaces and resolve the sequences of these DNA fragments by walking from the adaptors into unknown sequences (Metzker 2010). This technology does not rely on previous knowledge of the DNA to be sequenced, and hence can be used to discover previously unknown viruses. More importantly, the extremely high-throughput of this technology produces sequences of billions of nucleotides (nt) in a single run. Therefore, even though the cost per run is still prohibitive, that of each sample can be greatly reduced by pooling multiple samples into a single run. Furthermore, since plant viruses regardless of the nature of their genomes synthesize mRNAs in infected cells, profiling techniques like RNA-Seq that focus solely on rRNAdepleted cellular RNAs greatly reduce sequence complexities by avoiding non-transcribed host genome elements.

Here we report the results of a cost-effective assessment of soybean virus prevalence in Ohio by taking advantage of the high throughput RNA-Seq technology. A total of 259 soybean leaf samples were collected in two soybean-growing seasons (2011 and 2012) from 42 Ohio counties, and subjected to two RNA-Seq runs in order to obtain an updated view of soybean-infecting viruses in this state. This study permitted the identification with high confidence of BPMV and SVNV as the most prevalent soybean viruses, followed closely by TRSV and TSV.

Interestingly, SMV, found to be common in previous surveys (Giesler and Ziems 2006), was found in only one field used for germplasm propagation, suggesting that SMV is not a significant threat to soybeans in Ohio. We also found sporadic infection of soybeans by BYMV and ClYVV, two viruses known to infect soybeans in Asia, Europe, and South America, but have yet to be reported in the United States (Campos et al. 2014; Kyrychenko 2013). Finally, our sampling identified SPuV, a new virus associated with soybean production. These data will offer valuable guidance for management practices of soybean viruses.

\section{COLLECTION AND PROCESSING OF FIELD SAMPLES OF SOYBEAN FOR RNA-SEQ}

Depending on the number of soybean fields encountered in our scouting trips, samples were collected from one to five fields per county (Fig. 1, Tables 1 and 2). In counties in which more than two fields were chosen, the distances between any two fields were at least eight kilometers. For each field, at least two neighboring sides were scouted for at least one hundred meters, and leaves with virus-like symptoms were collected. For fields in which no plants showed virus-like symptoms, soybean leaf samples were selected without regard for appearance. Overall symptomless samples accounted for less than $10 \%$ of the total. Total RNA was extracted from each of the collected samples with the TRIsure reagent following the manufacturer's instructions (Bioline, Taunton, MA). The obtained RNA samples were then checked for concentration and quality with NanoDrop spectrophotometer (Thermo Scientific) and agarose gel electrophoresis.

\section{GENERATION AND ANALYSIS OF RNA-SEQ DATA}

To minimize the cost of sequencing, we used a two-step process to construct pools of RNA samples. First, an equal amount ( $1 \mu \mathrm{g}$ per sample) of RNA was withdrawn from each of the samples (up to 20) collected from fields of two to three neighboring counties, and pooled to make one regional pool. Altogether eight regional pools were generated for both 2011 and 2012. Then, $2 \mu \mathrm{g}$ of RNA was taken from every regional pool and further pooled into two Master Pools_-one for 2011 and one for 2012. The Master Pool RNAs were checked for RNA integrity, treated with DNase, and sent to the Roy J. Carver Biotechnology Center of University of Illinois at Urbana-Champaign for ribosomal RNA (rRNA) depletion, library construction, and sequencing on a HiSeq2000 platform.

Bioinformatic analyses of the RNA-Seq data were carried out using two different approaches. For the 2011 data, reads that match soybean mRNAs and rRNAs were removed with Bowtie (Langmead et al. 2009), and the remaining reads were trimmed to remove adaptor sequence, and the trimmed reads assembled into contigs using Trinity (Grabherr et al. 2011). These contigs were then subjected to BLASTx search against the NCBI viral RefSeq virus protein database using USEARCH (Edgar 2010).

For the 2012 data, a more user-friendly software package was adopted for bioinfomatic analysis. Specifically, raw reads were imported into CLC Bio Genomics Workbench v6.5.1 (Qiagen, Venlo, Netherlands) and trimmed for quality, adapter indexes, and poly(A) tails using default settings (ambiguous limit $=2$, quality limit $=0.05$ ). Reads matching soybean mRNAs and rRNAs were removed from the dataset by mapping preprocessed reads to the most recent soybean genome assembly (Glyma.Wm82.a2.v1). The unmapped reads were assembled de novo into contigs using two independent approaches: (i) the CLC Bio algorithm based on de Bruijn graphs and the optimized parameters of Word Size $=64$, Bubble Size $=500$, Length Fraction $=0.6$, Similarity Fraction $=$ 0.9; and (ii) Oases v0.2.08 with Kmer sizes of 53, 59, 65, 71, 77, 83 , and 89 (Schulz et al. 2012). To obtain the set of non-redundant transcripts for each assembly, reads $\geq 90 \%$ sequence similarity were collapsed into clusters and the longest read retrieved using CD-HIT-EST (Li and Godzik 2006). The two independent assemblies were collapsed into a final assembly using Minimus2 (Sommer et al. 2007). Contigs of viral origin were identified using desktop-downloaded BLASTx software against the NCBI viral RefSeq virus protein database $($ E-value $<1$ e-10).

\section{MAPPING THE DISTRIBUTION OF IDENTIFIED VIRUSES}

The viruses revealed through RNA-Seq and bioinformatic analyses were then mapped to their corresponding fields using PCR or RT-PCR, using the primers listed in Table 3. Specifically, the regional pools were first examined with virus-specific primers to narrow down the specific viruses to their corresponding region(s). The individual samples in these regional pools were then tested individually to complete the final distribution mapping.

\section{RNA-SEQ AS A ROBUST METHOD FOR SOYBEAN VIRUS SURVEYS}

Our primary goal for this study was to identify most, if not all, potential viruses that pose threats to soybean production in Ohio. To this end, we chose to use RNA-Seq as the primary tool for virus discovery because it would provide viral sequence information even for previously undescribed viruses for which no detection reagents are available. More importantly, the huge amount of data generated through high-throughput sequencing meant that samples collected from multiple locations could be combined into a limited number of sequencing attempts, thus greatly reducing the per-sample costs. Indeed, we were able to pool 108 and 151 RNA samples collected in 2011 and 2012, respectively, into two yearly pools, and obtained 88,102,967 and $170,075,625100-n t$ reads. BLASTx search revealed that about $0.37 \%$ of the 2011 reads $(324,832)$ and $1.76 \%$ of 2012 reads $(3,165,971)$ matched sequences of previously described plant viruses with a $P$ value cutoff of $1 \mathrm{e}-06$. These reads were further assembled into contigs and those shorter than $200 \mathrm{nt}$ were excluded from further analyses. Additionally, misidentified 
contigs of soybean origin were manually removed. As a result, 139 and 274 contigs of virus origin were identified from 2011 and 2012 samples, respectively. Sequences of these contigs formed the basis for further distribution mapping described below. These results demonstrated that high throughput RNA-Seq is a robust and cost-effective method for surveying viruses of soybean and other plants.

\section{INCIDENCE OF BPMV IN OHIO SOYBEAN FIELDS}

In both years, BPMV was found to be the most common virus. Indeed, over $93 \%$ of the 2011 virus reads, and more than $74 \%$ of the 2012 virus reads matched various BPMV isolates (Gu et al. 2002). Geographically, BPMV was found in 17 (of 24) and 12 (of 22) counties in 2011 and 2012, respectively (Fig. 1; Table 2 and 3). Previous studies have classified BPMV isolates into two subgroups (Gu et al. 2002). Interestingly, our results revealed an uneven prevalence of subgroup I and II genotypes, as an overwhelming majority of contigs of both years aligned more closely with subgroup II genotypes. In fact, all of the RNA2specific contigs $200 \mathrm{nt}$ or longer aligned preferably with sequences of subgroup II isolates deposited in GenBank ( $>97 \%$ sequence identity). Another notable characteristic of BPMV

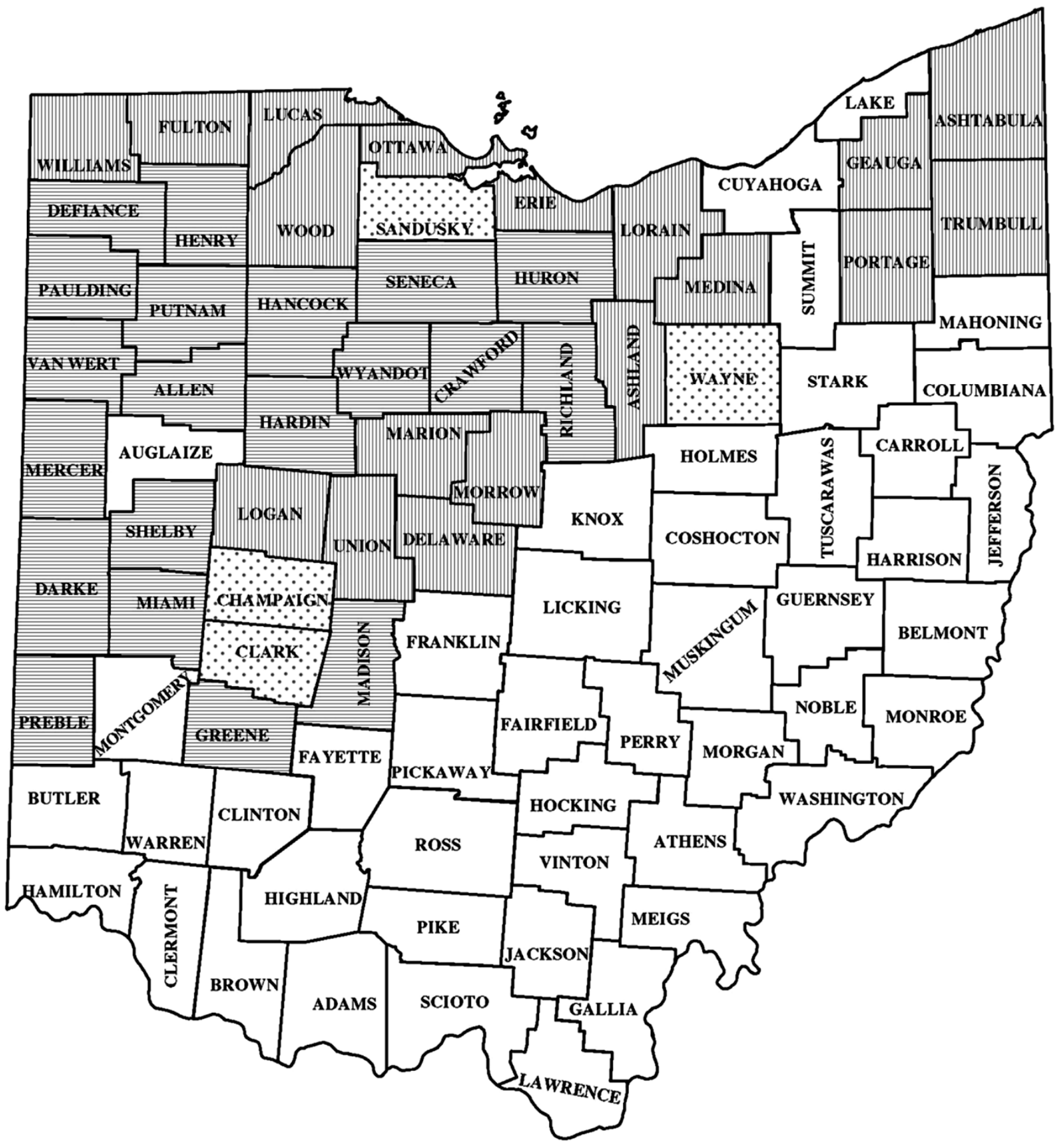

FIGURE 1

Counties of Ohio, USA, surveyed in the current study. Shown is a map of Ohio with counties surveyed in 2011 filled with horizontal lines, those surveyed in 2012 vertical lines. Counties surveyed both years are filled with gray dots. 
TABLE 1

County-level distribution of soybean viruses identified in 2011 samples.

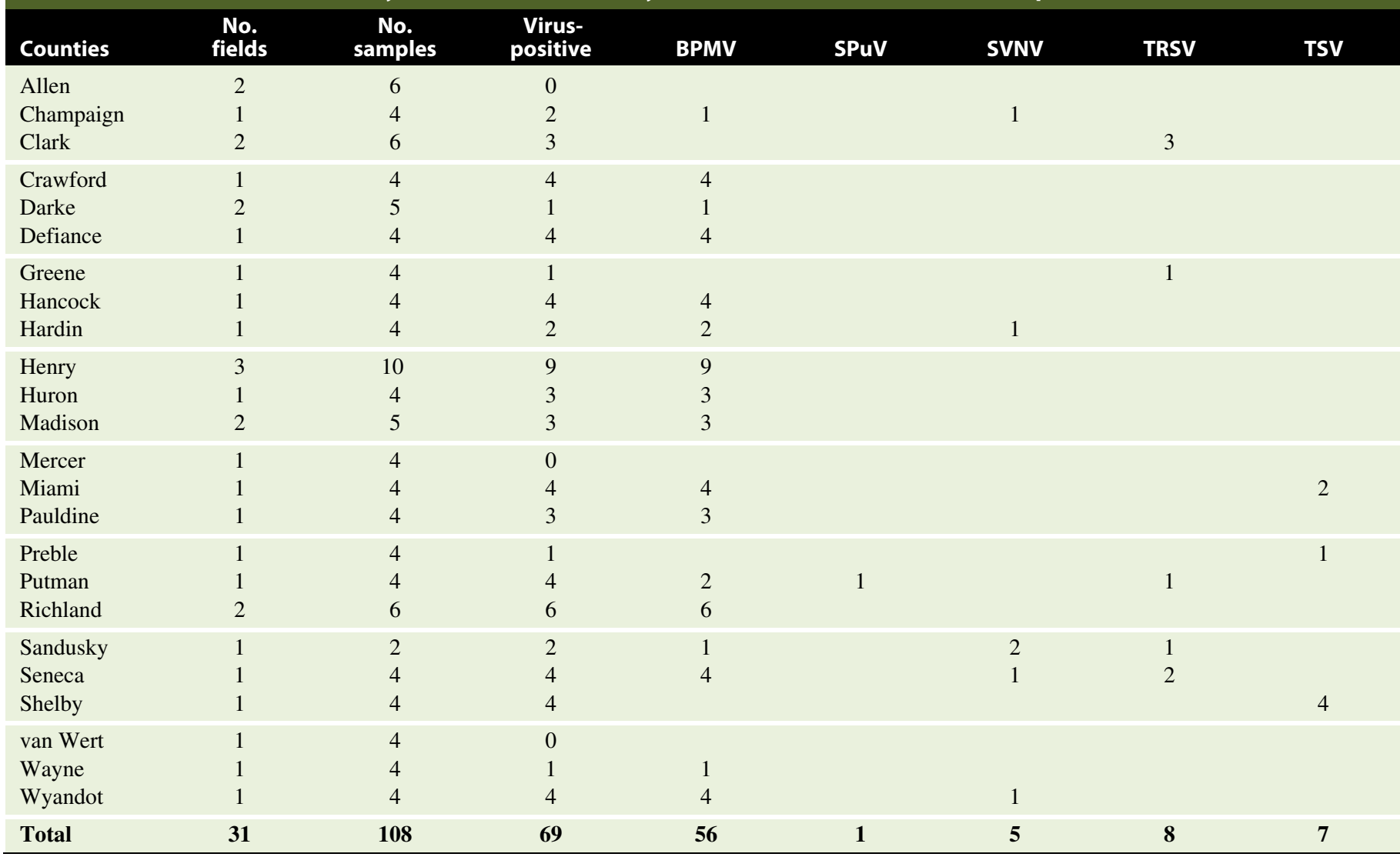

\begin{tabular}{|c|c|c|c|c|c|c|c|c|c|c|c|}
\hline & & Coun & y-level di: & bution & $\begin{array}{r}\text { TAB } \\
\text { soybea }\end{array}$ & uses id & fied in & 2 sam & & & \\
\hline Counties & $\begin{array}{l}\text { No. } \\
\text { fields }\end{array}$ & $\begin{array}{c}\text { No. } \\
\text { samples }\end{array}$ & $\begin{array}{c}\text { Virus } \\
\text { positive }\end{array}$ & AMV & BPMV & BYMV & CYVV & SMV & SVNV & TRSV & TSV \\
\hline Ashland & 2 & 6 & 5 & & 4 & & & & 2 & & \\
\hline Ashtabula & 2 & 6 & 2 & & & & & & 2 & & \\
\hline Champaign & 1 & 4 & 3 & & 3 & & & & 1 & & \\
\hline Erie & 2 & 6 & & & 4 & & & & & 1 & \\
\hline Fulton & 2 & 6 & 0 & & & & & & & & \\
\hline Geauga & 2 & 6 & 4 & & & & & & 4 & & \\
\hline Logan & 2 & 6 & 4 & & 4 & & & & 3 & & \\
\hline Lorain & 2 & 6 & 4 & & & & & & 3 & 2 & \\
\hline Morrow & 2 & 6 & 6 & & 4 & & & & 5 & 3 & \\
\hline Ottawa & 2 & 6 & 2 & & 1 & & & & 1 & & \\
\hline Portage & 2 & 6 & 3 & & & & & & 3 & & \\
\hline Sandusky & 2 & 6 & 0 & & & & & & & & \\
\hline Trumbull & 5 & 15 & 7 & & 1 & & & & 6 & & \\
\hline Union & 2 & 6 & 5 & & & & 2 & & 5 & & \\
\hline Wayne & 3 & 10 & & 2 & & & & & & & \\
\hline Williams & 2 & 6 & 0 & & & & & & & & \\
\hline Wood & 2 & 6 & 6 & & 2 & & & & 1 & & 3 \\
\hline Total & 49 & 151 & 84 & 2 & 38 & 2 & 2 & 2 & 50 & 16 & 5 \\
\hline
\end{tabular}


contigs is their extreme sequence diversity. In fact, most of the assembled contigs were under $500 \mathrm{nt}$ long, as widespread singlenucleotide polymorphisms made it difficult to assemble full length genomes with sufficient confidence. These data suggest that BPMV has become associated with Ohio soybean production for some time, allowing for independent evolution of diverse field strains.

\section{INCIDENCE OF SVNV}

SVNV has attracted nationwide attention since its discovery less than ten years ago (Tzanetakis et al. 2009; Zhou et al. 2011). In our samples, SVNV was found in five counties in 2011 and 17 counties in 2012 (Tables 1 and 2, Fig. 2). In all, SVNV was present in at least 21 counties across the state, suggesting that it is not a newly introduced virus. Rather, its presence was likely ignored in the past. Most of the 2011 reads could be assembled into three contigs of 7,551, 4,937, and 1,554 nt, corresponding to partial sequences of L, M, and S segments of the SVNV genome. However, the 2012 data showed more diversity in SVNV as 24 SVNV-specific contigs ranging from 200 to 760 nt could not be integrated into longer assemblies because of single-nucleotide polymorphisms. Pairwise alignments suggest that at least two different SVNV genotypes were present, with their L, M, and S segments sharing approximately $99 \%, 98 \%$, and $96 \%$ nt level identities, respectively.

\section{INCIDENCE OF TRSV}

TRSV was the third most common virus of soybean in our samples, found in fields of five counties in 2011(Table 1) and six counties in 2012 (Table 2; Fig. 2C). These counties were fairly evenly distributed among the Ohio soybean-producing counties, though slightly more concentrated near Lake Erie shore. A striking characteristic associated with TRSV is the extreme sequence diversity. Indeed, in spite of limited sequencing depth, three different RNA1 genotypes can be clearly discerned from 2011 samples. Four additional RNA1 genotypes were identified in 2012 samples. Furthermore, pairwise comparisons revealed that these seven RNA1 genotypes share less than $90 \%$ sequence similarity with each other within a 250 -nt homologous region shared by the seven partial sequences. Indeed, different pairs of primers had to be used to map the specific genotypes to their respective locations (see Mapping the Distribution of Identified Viruses and Table 3). These results strongly suggest that once introduced to a given location, TRSV evolved independent of each other with limited exchange of genetic materials among different genotypes.

\section{INCIDENCE OF TSV}

TSV was found in multiple Ohio soybean fields, and in both years. Specifically, it was in three counties (Miami, Preble, and Shelby) surveyed in 2011, and two counties (Clark and Wood) surveyed in 2012 (Table 1 and 2, Fig. 2D). It is interesting to note that all five TSV-positive counties are located within the western third of Ohio. It remains to be determined whether this specific geographic location contributed to TSV incidences. Another noteworthy observation was that in both years at least two distinct TSV genotypes were isolated, presumably associated with different field sites. In fact, the two genotypes isolated in 2011 were $89 \%, 83 \%$, and $89 \%$ identical for RNA1, RNA2, and RNA3, respectively. The identity levels for the two 2012 genotypes were $90 \%, 88 \%$, and $90 \%$. Interestingly, although the isolates of a particular year were quite dissimilar to each other, they appear to fall into two distinct clades as year-to-year comparison revealed each of the 2011 isolates could match one of the 2012 isolates with 97 to $99 \%$ identities.

\section{ISOLATED CASES OF AMV, SMV, BYMV, CLYVV, AND SPUV}

Unlike the viruses described above, these five viruses were each found in just one field. That AMV and SMV were so rare in Ohio soybean fields was surprising as both have been reported to be relatively common soybean pathogens in other states (Giesler and Ziems 2006; Malapi-Nelson et al. 2009). Closer examination revealed that the AMV-positive samples were collected from a field that was part of OARDC experimental farms, with an alfalfa plot nearby. Conversely, the SMV-positive samples were collected from a field in the OARDC Western Station used for propagation of germplasm, and hence could be caused by contaminated seed stock(s). In short, our results suggest that neither AMV nor SMV was associated with large-scale field soybeans in Ohio.

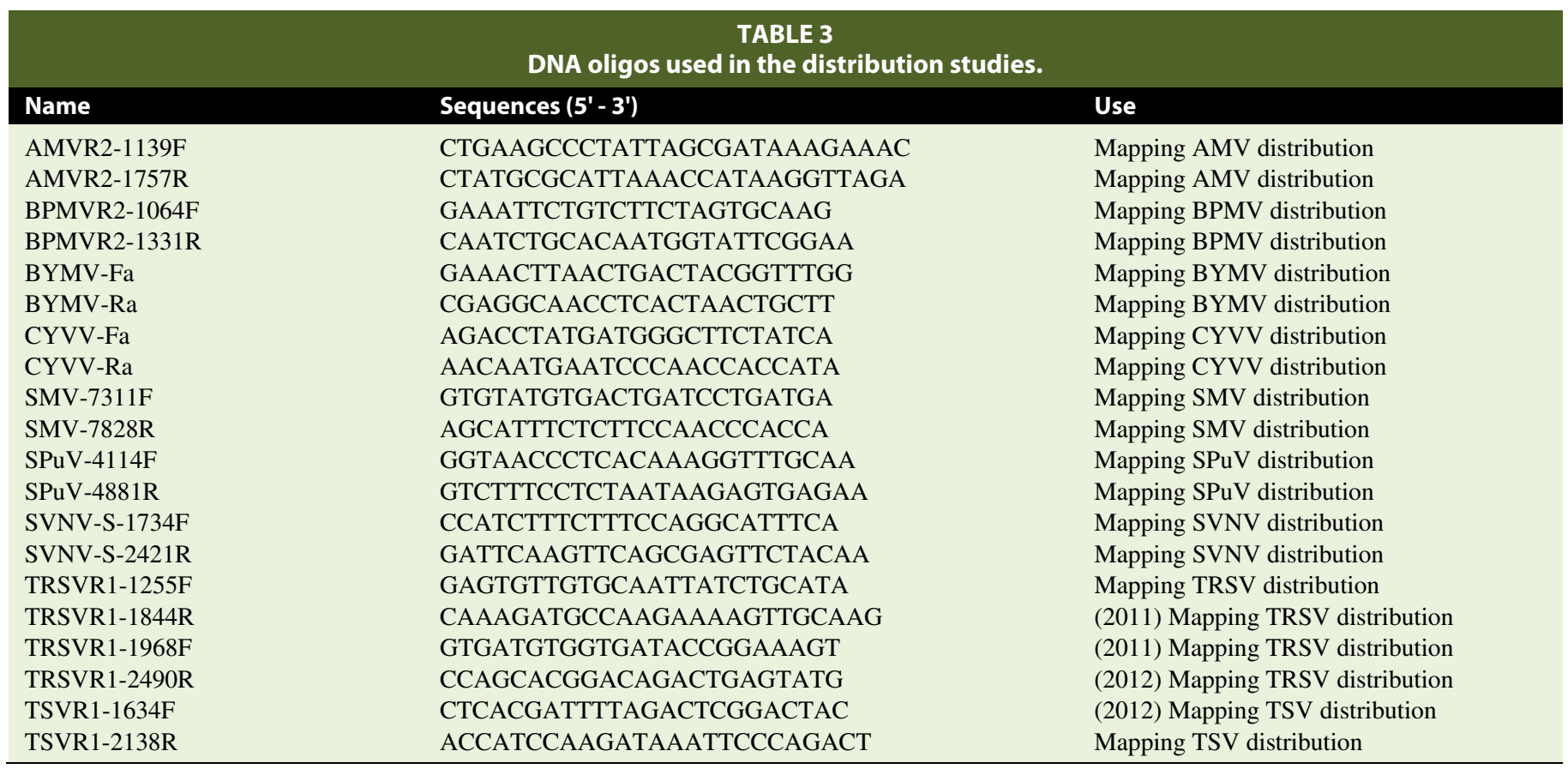


The discovery of BYMV and ClYVV in soybean is noteworthy as neither has been reported to infect soybean in Ohio. BYMV as a soybean pathogen has been reported overseas (Campos et al. 2014). Within the United States, BYMV was reported to be present in field-grown soybeans in Illinois (http://ipm.illinois.edu /diseases/series500/rpd505/). Our BYMV isolate was found in a

A

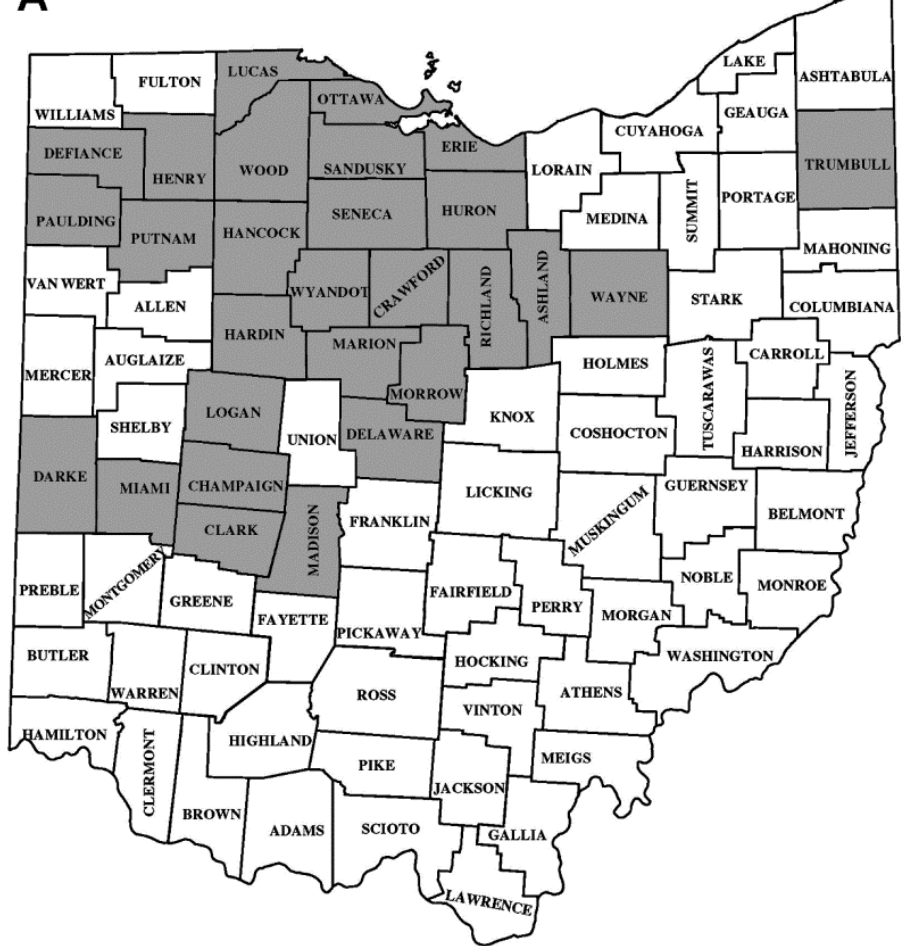

C

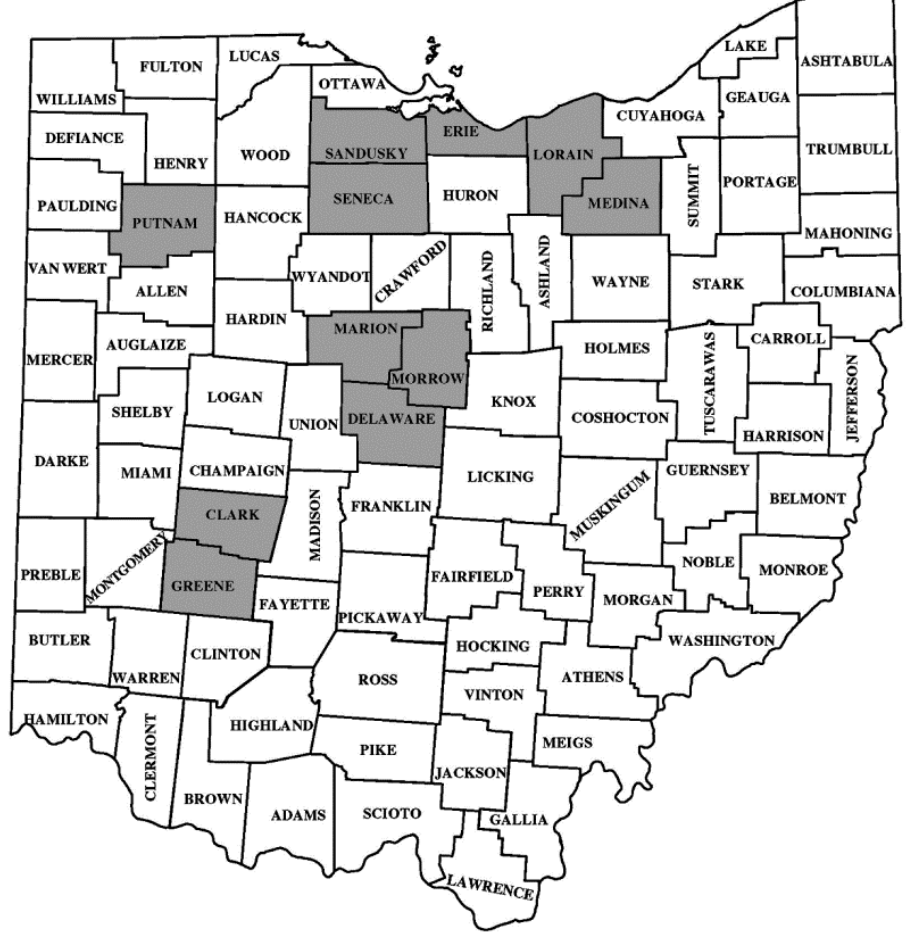

soybean field in Delaware County in central Ohio. All BYMVrelated RNA-Seq reads could be assembled into a near full-length (9,517-nt) BYMV sequence that shares 93\% sequence identity with the closest BYMV isolate (GenBank Accession No.

HG970850.1).
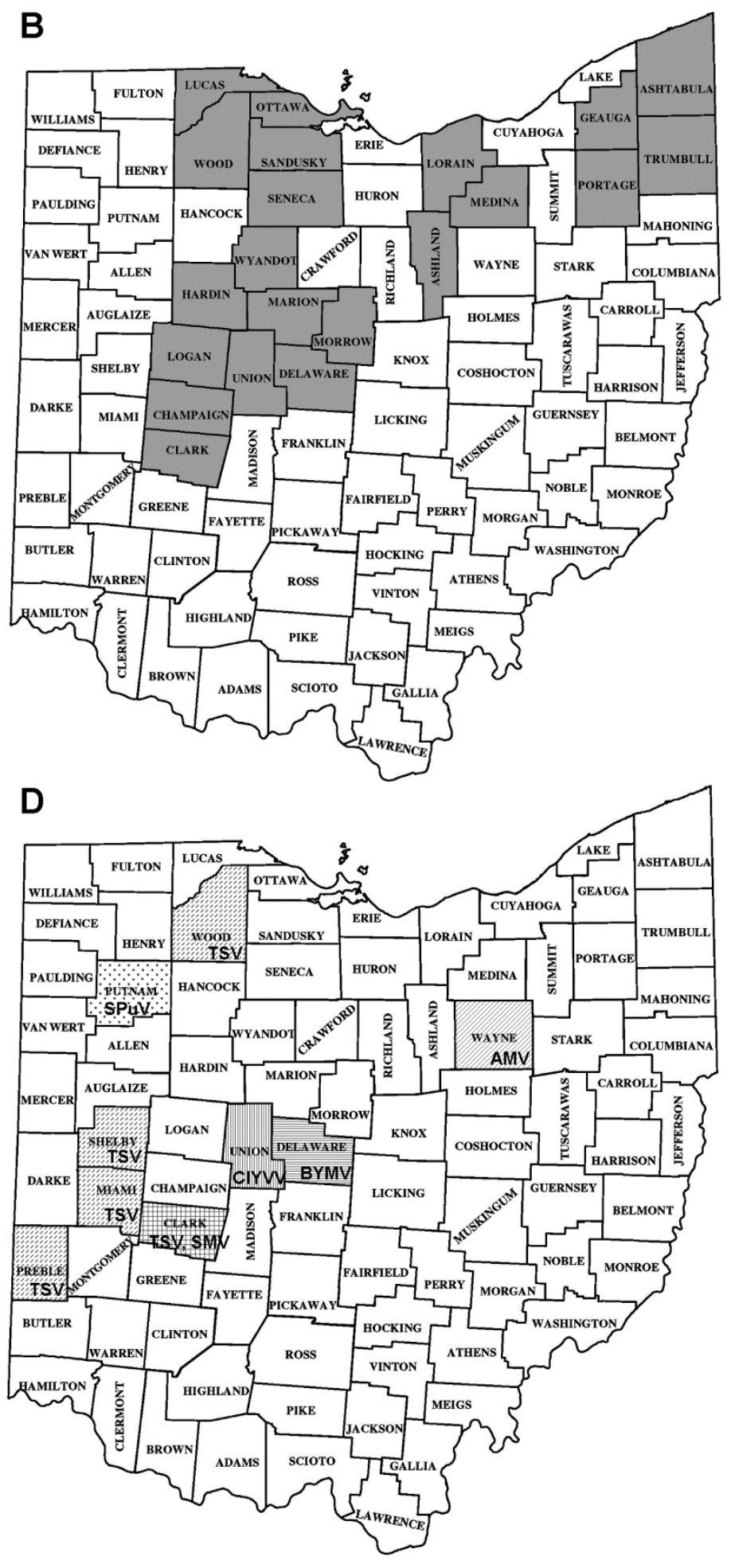

FIGURE 2

Distribution patterns in Ohio counties of (A) BPMV, (B) SVNV, (C) TRSV, and (D) other viruses. In A, B, and C, counties where the corresponding viruses were discovered are filled with gray. In D, counties where TSV were found are filled with grids of dashed lines (Miami, Preble, Shelby, and Wood), or solid lines (Clark) where SMV was also found. Counties where AMV (Wayne), BYMV (Delaware), and CIYVV (Union) were found are filled with slanted, horizontal, and vertical lines, respectively. The Putnam County where SPuV was discovered are filled with dots. 
ClYVV has been associated with soybean diseases in Japan and South Korea (Sasaya et al. 1997; Shin et al. 2014). Within the continental United States, it was identified in clover and snap beans but has yet to be found in soybean. The CIYVV-positive samples were collected in a single field in Union County in central Ohio. Interestingly, two distinct CIYVV genotypes sharing 93\% sequence identity could be assembled from the RNA-Seq reads. It is worth noting that both samples that tested positive for ClYVV were also positive for SVNV.

Finally, the discovery of SPuV was reported earlier (Han et al. 2012). The mode of transmission, as well as potential pathology of this virus remains to be elucidated as we have so far been unsuccessful in mechanically transmitting this virus to new plants. However, its association with soybean does not appear to be isolated as it was also identified from samples collected in other states (L. L. Domier, unpublished).

\section{LIMITED SCALE OF VIRUS DISEASES IN OHIO SOYBEAN FIELDS}

Overall, as judged by symptoms, virus diseases were relatively uncommon in Ohio soybean fields in both years (2011 and 2012). In fact, plants with virus symptoms were often limited to a few edge rows, or sometimes even to a few plants, typically accounting for a very small fraction of the fields. The drought condition in 2012 was associated with a sharp increase in SVNV incidences. Nevertheless, the symptomatic plants were still limited to mostly fewer than 10 rows on one side of the fields. We speculate that this pattern of disease distribution might be caused by arthropod vectors that migrate from weeds or wooded areas to young soybean seedlings as they emerge. While symptoms characteristic of SVNV were commonly observed in mature leaves, they could have been due to infections that occurred in younger plants. Finally, the absence of SbDV in our soybean samples is consistent with reports from other states, and possibly reflects the inefficiency of the soybean aphid (Aphis glycines Matsumura) as a SbDV vector (Harrison et al. 2005; Damsteegt et al. 2011).

\section{MIXED INFECTIONS OF MULTIPLE VIRUSES}

Samples positive for SVNV frequently contained two or more viruses. Indeed, five out of six SVNV-positive samples in 2011 contained at least one additional virus: three co-infected with BPMV (from Hardin, Wyandot, and Sandusky counties); one with TRSV (Sandusky County; dark gray); and one with both BPMV and TRSV (from Seneca County; yellow). In 2012, 18 of the 50 SVNV-positive samples contained other viruses: eight with BPMV; four with TRSV; and three others with both BPMV and TRSV. Additionally, SVNV also co-existed with CIYVV in both ClYVV-positive samples and BYMV in one of the two BYMVpositive samples. Furthermore, two of the 2011 samples and one of the 2012 samples contained BPMV and TSV, one 2012 sample contained BPMV and TRSV, another 2012 sample contained BPMV and SMV, and yet another 2012 sample contained BPMV, SMV, and TRSV. In conclusion, although overall plants showing virus symptoms were uncommon, those that did often contained more than one virus. Therefore, it is possible that soybean plants infected with one virus might stay symptomless.

\section{CONCLUDING REMARKS}

We report an extensive sampling of soybean-infecting viruses in Ohio soybean fields during the 2011 and 2012 growing seasons. This study confirmed the widespread presence of BPMV, SVNV, and TRSV in the fields, although the scale of infections was relatively limited. A substantial increase in the number of fields positive for SVNV was observed in 2012, possibly as a result of the unusually dry and hot weather that summer, which could favor the propagation of SVNV-transmitting arthropod vectors (thrips). The only other virus found in more than one field, and in both years, was TSV. By contrast, AMV and SMV, which were thought to be common soybean pathogens, were only found sporadically in Ohio. Finally, isolated incidences of ClYVV, BYMV, and SPuV infections were also observed. These data are expected to offer guidance to the diagnosis and management of soybean virus problems in Ohio and other neighboring states.

\section{ACKNOWLEDGMENTS}

We thank Drs. Peg Redinbaugh and Lucy Stewart for sharing equipment, and the Biotechnology Center of the University of Illinois for carrying out the high throughput sequencing. This study was supported in part by a grant from Ohio Soybean Council. We also thank the Center for Applied Plant Science, The Ohio State University, for partial support of supplies and travels. Salaries and partial research support for F. Qu and A. Dorrance were provided by State and Federal Funds appropriated to the Ohio Agricultural Research and Development Center, The Ohio State University.

GenBank Accession Numbers: JQ926983; KT429435; KT445965 to 445969.

\section{LITERATURE CITED}

Boonham, N., Kreuze, J., Winter, S., van der Vlugt, R., Bergervoet, J., Tomlinson, J., and Mumford, R. 2014. Methods in virus diagnosis: From ELISA to next generation sequencing. Virus Res. 186:20-31.

Bradshaw, J. D., Rice, M. E., and Hill, J. H. 2008. Evaluation of management strategies for bean leaf beetles (Coleoptera: Chrysomelidae) and bean pod mottle virus (Comoviridae) in soybean. J. Econ. Entomol. 101:1211-1227.

Campos, R. E., Bejerman, N., Nome, C., Laguna, I., and Rodriguez Pardina, P. 2014. Bean yellow mosaic virus in soybean from Argentina. J. Phytopathol. 162:322-325.

Damsteegt, V. D., Stone, A. L., Kuhlmann, M., Gildow, F. E., Domier, L. L., Sherman, D. J., Tian, B., and Schneider, W. L. 2011. Acquisition and transmissibility of U.S. Soybean dwarf virus isolates by the soybean aphid, Aphis glycines. Plant Dis. 95:945-950.

Edgar, R. C. 2010. Search and clustering orders of magnitude faster than BLAST. Bioinformatics 26:2460-2461

Gagarinova, A. G., Babu, M., Poysa, V., Hill, J. H., and Wang, A. 2008. Identification and molecular characterization of two naturally occurring Soybean mosaic virus isolates that are closely related but differ in their ability to overcome Rsv4 resistance. Virus Res. 138:50-56.

Ghabrial, S. A., Pickard, C. M., and Stuckey, R. E. 1977. Identification and distribution of virus diseases of soybean in Kentucky. Plant Dis. Rep. 61:690-694.

Giesler, L. J., and Ziems, A. D. 2006. Incidence of Alfalfa mosaic virus, Bean pod mottle virus, and Soybean mosaic virus in Nebraska soybean fields. Plant Health Prog. doi:10.1094/PHP-2006-0424-01-HM.

Grabherr, M. G., Haas, B. J., Yassour, M., Levin, J. Z., Thompson, D. A., Amit, I., Adiconis, X., Fan, L., Raychowdhury, R., Zeng, Q., Chen, Z., Mauceli, E., Hacohen, N., Gnirke, A., Rhind, N., di Palma, F., Birren, B. W., Nusbaum, C., Lindblad-Toh, K., Friedman, N., and Regev, A. 2011. Full-length transcriptome assembly from RNA-Seq data without a reference genome. Nat. Biotechnol. 29:644-652.

Gu, H., Clark, A. J., de Sá, P. B., Pfeiffer, T. W., Tolin, S., and Ghabrial, S. A. 2002. Diversity among isolates of Bean pod mottle virus. Phytopathology 92:446-452.

Han, J., Domier, L. L., Dorrance, A., and Qu, F. 2012. Complete genome sequence of a novel pararetrovirus isolated from soybean. J. Virol. 86:9555.

Harrison, B., Steinlage, T. A., Domier, L. L., and D'Arcy, C. J. 2005. Incidence of Soybean dwarf virus and identification of potential vectors in Illinois. Plant Dis. 89:28-32.

Hill, J. H., Koval, N. C., Gaska, J. M., and Grau, C. R. 2007. Identification of field tolerance to Bean pod mottle and Soybean mosaic viruses in soybean. Crop Sci. 47:212-218.

Hill, J. H., and Whitham, S. A. 2014. Control of virus diseases in soybean. Adv. Virus Res. 90:355-390. 
Kehoe, M. A., Coutts, B. A., Buirchell, B. J., and Jones, R. A. 2014. Plant virology and next generation sequencing: Experiences with a potyvirus. PLOS One 9:e104580.

Kyrychenko, A. M. 2013. The characterization of bean yellow mosaic virus isolated from soybean. Mikrobiol. Zh. 75:68-73.

Langmead, B., Trapnell, C., Pop, M., and Salzberg, S. L. 2009. Ultrafast and memory-efficient alignment of short DNA sequences to the human genome. Genome Biol. 10:R25.

Li, W., and Godzik, A. 2006. CD-HIT: A fast program for clustering and comparing large sets of protein or nucleotide sequences. Bioinformatics 22:1658-1659.

Malapi-Nelson, M., Wen, R.-H., Ownley, B. H., and Hajimorad, M. R. 2009. Co-infection of soybean with Soybean mosaic virus and Alfalfa mosaic virus results in disease synergism and alteration in accumulation level of both viruses. Plant Dis. 93:1259-1264.

Metzker, M. L. 2010. Sequencing technologies - the next generation. Nat. Rev. Genet. 11:31-46.

Sasaya, T., Shimizu, T., Nozu, Y., Nishigushi, M., Inouye, N., and Koganezawa, H. 1997. Biological, serological, and molecular variabilities of clover yellow vein virus. Phytopathology 87:1014-1019.
Schulz, M. H., Zerbino, D. R., Vingron, M., and Birney, E. 2012. Oases: Robust de novo RNA-seq assembly across the dynamic range of expression levels. Bioinformatics 28:1086-1092.

Shin, J.-C., Kim, M.-K., Kwak, H.-R., Choi, H.-S., Park, C.-Y., Lee, S.-H., and Cha, B. J. 2014. First report of clover yellow vein virus on Glycine max in Korea. Plant Dis. 98:1283.

Sommer, D. D., Delcher, A. L., Salzberg, S. L., and Pop, M. 2007. Minimus: A fast, lightweight genome assembler. BMC Bioinformatics 8:64.

Tzanetakis, I. E., Wen, R.-H., and Newman, M. 2009. Soybean vein necrosis virus: A new threat to soybean production in southeastern United States? Phytopathology 99:S131.

Wilson, R. F. 2008. Soybean: Market driven research needs. Pages 3-15 in: Genetics and Genomics of Soybean. G. Stacy, ed. Springer. New York.

Zhang, C., Gu, H., and Ghabrial, S. A. 2007. Molecular characterization of naturally occurring RNA1 recombinants of the comovirus Bean pod mottle virus. Phytopathology 97:1255-1262.

Zhou, J., Kantartzi, S. K., Wen, R.-H., Newman, M., Hajimorad, M. R., Rupe, J. C., and Tzanetakis, I. E. 2011. Molecular characterization of a new tospovirus infecting soybean. Virus Genes 43:289-295.

Zhou, J., and Tzanetakis, I. E. 2013. Epidemiology of soybean vein necrosisassociated virus. Phytopathology 103:966-971. 